\title{
Strength analysis of a quasi-autonomous lamp post with the use of CAD/CAE systems
}

\author{
Analiza wytrzymałościowa quasi-autonomicznego słupa \\ oświetleniowego z wykorzystaniem systemów CAD/CAE
}

WALDEMAR DUDDA
JERZY DOMAŃSKI*
DOI: https://doi.org/10.17814/mechanik.2017.7.84

\begin{abstract}
Presented is the stress analysis of the steel lighting column, that the set of wind microturbine with generator and the set of photovoltaic panels was installed on. Works were done within the project entitled „Functional models and investigations of the construction of a quasi-autonomous lighting or signalling point".
\end{abstract}

KEYWORDS: wind-turbine, photovoltaic panel, lamppost, stress

On typical poles designed for lighting fixtures, wind turbines can rarely be installed. The increase in stress values, especially in the base of the column, depends on the configuration and location of the turbine and in some cases exceeds the limit value [1]. The addition of photovoltaic panels will further increase the stresses due to wind pressure. In addition, in July 2009, a change to $\mathrm{Az} 1$ was made to the wind standard PN-77/B02011 (Load in static calculations. Wind loads). It includes, among others, a new map of Poland's division into wind zones, new, higher values of wind speed, correction of exposure coefficients and load factor [2]. Therefore, poles before July 2009, after the installation of a wind turbine and/or photovoltaic panel, would have to meet even more stringent requirements.

The purpose of the described work is the strength analysis of the chosen concept of steel lighting pole adapted for assembly of photovoltaic panels and the set of micro-wind turbine with generator. The analysis was carried out using CAD/CAE (SolidWorks Simulation) tools and according to the standard [3] for the most disadvantageous case of load impact.

\section{Subject of study}

The concept (fig. 1) of a $12 \mathrm{~m}$ round and $12 \mathrm{~m}$ high, made of sheet steel of the type S275JR, with a wall thickness of $4 \mathrm{~mm}$, with external diameters of $\varnothing 250 \mathrm{~mm}$ and $\varnothing 60 \mathrm{~mm}$. The boom (2) rigidly connected to the pole is made of a pipe with a diameter of $\varnothing 40 \mathrm{~mm}$ and a wall thickness of $3 \mathrm{~mm}$. At the end of the boom, an LED lantern (3) is attached. A set of wind turbine and generator (4) is attached to the flange end of the column. In the middle of the column there is a fixed bracket (5) with photovoltaic panels (6). The bracket is made of a pipe with a diameter of $\varnothing 50 \mathrm{~mm}$ and a wall thickness of 3 $\mathrm{mm}$, from a cold angle bracket of $20 \times 20 \times 2 \mathrm{~mm}$.

\footnotetext{
* Dr inż.Waldemar Dudda (dudda@uwm.edu.pl), dr inż. Jerzy Domański (jdom@uwm.edu.pl) - Wydział Nauk Technicznych Uniwersytetu Warmińsko-Mazurskiego
}

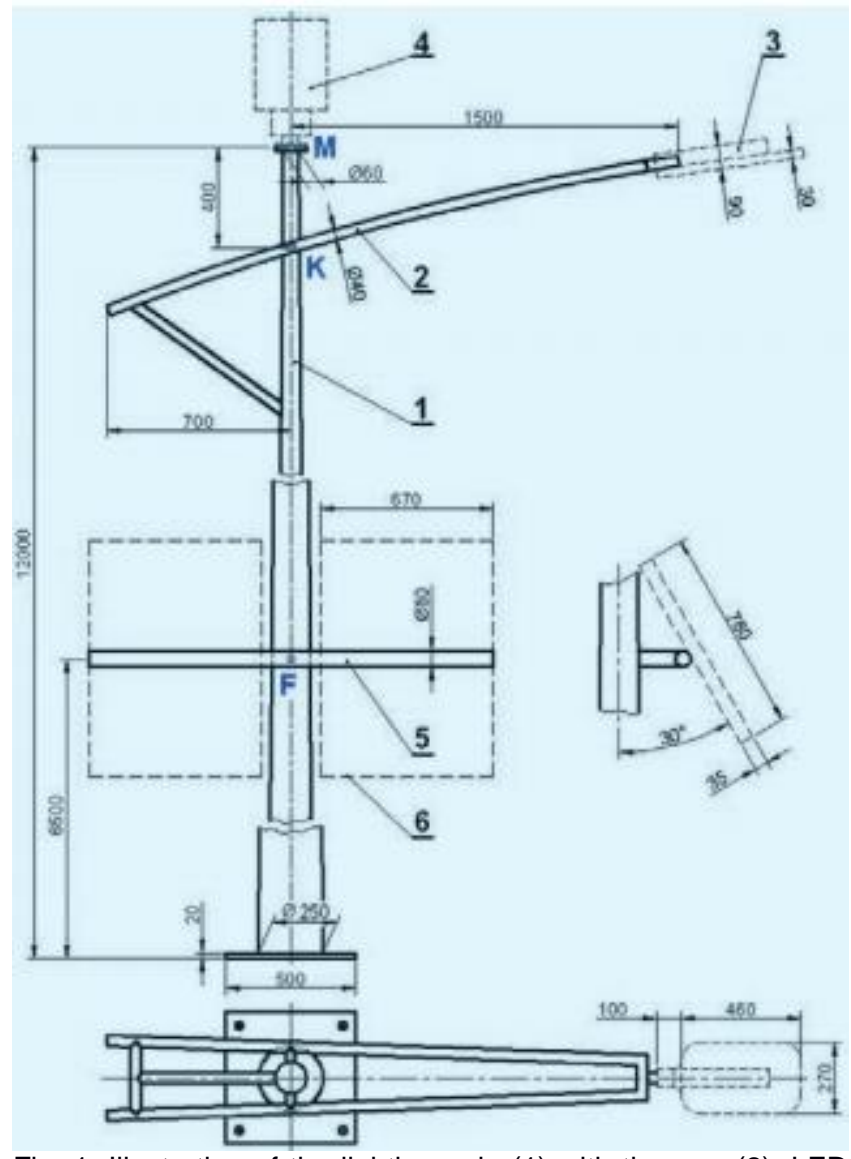

Fig. 1. Illustration of the lighting pole (1) with the arm (2), LED lantern (3), turbine (4) and bracket (5) with photovoltaic panels (6)

\section{Construction load}

An important part of the analysis is the determination of the value and the location of the application of all load components acting on the column. The load on the structure consists of the weights of all the elements of the structure of the column with the turbine and photovoltaic assemblies as well as the weight of the snow and the wind pressure on the said elements.

The procedure for determining wind load and own weight was carried out in accordance with PN EN 40-3$1: 2000$. It recommends that the pole is rigidly fixed to the 
ground, and the brackets are rigidly connected to the post. In analytical calculations, the moments from wind pressure and own weights should be calculated by appropriate distribution of the loads acting on the posts, brackets, lanterns, etc. For this purpose, the post is divided into elevation sections of no more than $2 \mathrm{~m}$. Then, for each $i$-th segment, gravity and wind force individually using the correct volume, field, shape coefficients, wind pressure, etc. The loads of the supports and other components are reduced to the center of the cross-section of the pole at their position.

\section{Characteristic wind pressure}

The pressure of the wind pressure has been determined in accordance with PN EN 40-3-1:2000 from the dependence:

$$
q(z)=\delta \cdot \beta \cdot f \cdot C e_{(z)} \cdot q_{(10)}
$$

where: $\delta$ - coefficient of scale effect (for column height $H$ $=12 \mathrm{~m}, \delta=0.88$ ), $\beta$ - dynamic factor (from graph $\beta=$ 1.5), $f$ - topographic coefficient (for a height decrease of less than $5 \mathrm{~m} f=1$ ), $C_{e(z)}$ - exposure index (depending on the category of the area and height of $Z_{S I}$ measure of the $i$-th section above ground level - cat. II - rural areas with individual buildings agricultural or trees - array), $q_{(10)}$ - the reference pressure velocity, the values of which are determined by the formula:

$$
q_{(10)}=0,5 \cdot \rho \cdot C_{s}^{2} \cdot V_{r e f}^{2} \quad\left[\mathrm{~N} / \mathrm{m}^{2}\right]
$$

where: $\rho$ - density of air $\left(\rho=1.25 \mathrm{~kg} / \mathrm{m}^{3}\right), C_{s}$ - conversion factor (for lighting columns $C_{s}=0.959$ ), $V_{\text {ref }}$ - reference speed (determined from wind maps, according to [3 wind maps PN] for the first wind zone $-V_{\text {ref }}=22 \mathrm{~m} / \mathrm{s}$ ). For analytical calculations, the force of wind pressure on the $i$-th section of the column/bracket, etc., was determined from the relationship:

$$
P_{i}=A_{i} \cdot c_{i} \cdot q(z)
$$

where: $A_{i}$ - field of the stem / column support section, etc. on the plane perpendicular to the wind direction, $c_{i}$ shape factor for the considered column/bracket section.

In CAE analysis, the wind load is realized by the wind load of the $i$-th section of the column/bracket, etc. by the resulting pressure according to the formula:

$$
q_{w}(z)=c_{i} \cdot q(z)
$$

The pole was divided into elevated sections; the coordinates of the projections of the surface projections $\mathrm{Ai}$ of the column sections on the plane perpendicular to the wind direction were calculated. The characteristic and accidental pressures, shape coefficients and forces of force, the values of which are given in the table, were determined.
TABLE. Characteristic $q(z)$ and resultant $q_{w}(z)$ of velocity pressure

\begin{tabular}{|c|c|c|c|c|c|c|c|}
\hline$z, m$ & $z_{s i} m$ & $C e_{(z)}$ & $\begin{array}{c}q(z), \\
\mathrm{N} / \mathrm{m}^{2}\end{array}$ & $c_{i}$ & $A_{i}$ & $P_{i}, \mathrm{~N}$ & $\begin{array}{c}q_{w}(z), \\
\mathrm{N} / \mathrm{m}^{2}\end{array}$ \\
\hline 12,0 & 12,000 & 2,47 & 907,4 & 1,2 & 0,000 & 0,0 & 1088,8 \\
\hline 11,6 & 11,796 & 2,458 & 903,0 & 1,2 & 0,0253 & 27,4 & 1083,6 \\
\hline 10,5 & 11,028 & 2,41 & 885,3 & 1,2 & 0,082 & 87,6 & 1062,4 \\
\hline 9,5 & 9,986 & 2,35 & 863,3 & 1,13 & 0,092 & 89,4 & 975,5 \\
\hline 8,5 & 8,988 & 2,29 & 841,2 & 1,02 & 0,108 & 92,2 & 858,1 \\
\hline 7,5 & 7,989 & 2,21 & 811,9 & 0,92 & 0,123 & 92,1 & 746,9 \\
\hline 6,5 & 6,500 & 2,13 & 782,5 & 0,81 & 0,000 & 0,1 & 633,8 \\
\hline 5,5 & 5,991 & 2,04 & 749,4 & 0,7 & 0,155 & 81,3 & 524,6 \\
\hline 4,5 & 4,992 & 1,93 & 709,0 & 0,67 & 0,171 & 81,2 & 475,0 \\
\hline 3,5 & 3,993 & 1,80 & 661,2 & 0,57 & 0,187 & 70,4 & 376,9 \\
\hline 2,5 & 2,993 & 1,80 & 661,2 & 0,503 & 0,203 & 67,4 & 332,6 \\
\hline 1,5 & 1,994 & 1,80 & 661,2 & 0,505 & 0,218 & 72,9 & 333,9 \\
\hline 0,5 & 0,994 & 1,80 & 661,2 & 0,51 & 0,234 & 79,0 & 337,2 \\
\hline 0,0 & 0,249 & 1,80 & 661,2 & 0,52 & 0,123 & 42,3 & 343,8 \\
\hline
\end{tabular}

\section{Load of the pole with the turbine with generator}

The load from the own weight and wind pressure to the turbine generator set (designated by the turbine design team within the project) was reduced to the upper $M$ end point (fig. 1) and shown in fig. $2 a$.

Such defined load was used both in analytical and numerical calculations. The load from the own weight, snow and wind pressure on the boom and lantern has been reduced to the point $K$ of the cross-section of the column (fig. 1) and shown in fig. 2b. Similarly, the load from own weight, snow and wind pressure on the bracket and photovoltaic panels has been reduced to the point $F$ of the cross-section of the column (fig. 1) and shown in fig. 2c.
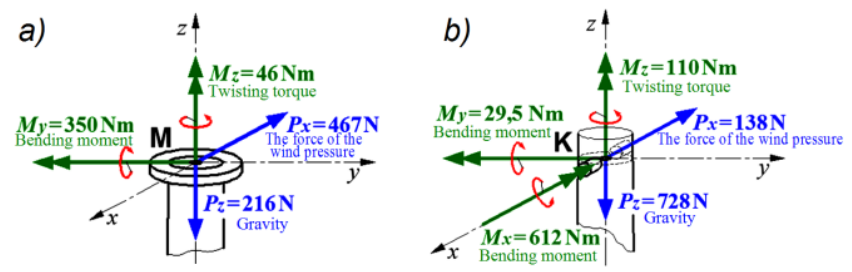

c)

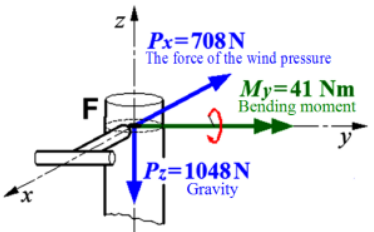

Fig. 2. Load reduction to points: a) $\mathrm{M}, b) \mathrm{K}, c$ ) $\mathrm{F}$ of the pole column 
The unit load was assumed to be $Q=1.6 \mathrm{kN} / \mathrm{m}^{2}$ in accordance with PN-80/B-02010/Az1:2006 for the IV zone according to the snow map (Warmia and Mazury area). Snow weights on the jib and lighthouse were calculated from the dependence:

$$
P_{\dot{s}}=A_{\dot{s}} \cdot q_{\dot{s}}
$$

where: $A_{s}$ - area of longitudinal section of arm and lantern.

On the contrary, for photovoltaic panels snow weights were determined from the following relationships:

$$
P_{s p f}=A_{p f} \cdot q_{\dot{s}} \cdot \cos \alpha_{p f}
$$

where: $A_{p f}$ - area of panels, $\alpha_{p f}$ - angle of inclination of panels to the level.

The load defined in fig. $2 b, c$ is used only in analytical calculations. On the other hand, in the numerical calculations, the option of automatic gravity integration was activated (for the elements loaded with snow, the unit weight was taken into account), and the wind effect was realized by the wind velocity incident pressure determined for the center coordinate of the plan view of the element in question perpendicular to the wind direction.

\section{Results of strength analysis}

Strength analysis was performed in two ways. An analytical stress was first determined by calculating the internal forces in the cross sections at the beginning and the end of each section of the column, to which the pole was divided. On the basis of the normal forces (along the $z$ axis), the bending moments (in the $x z$ and $y z$ planes) and the torsion (around the $z$ axis), the corresponding stresses are determined: $\sigma(N), \sigma\left(M_{g x z}\right), \sigma\left(M_{g} y z\right), T\left(M_{s}\right)$ and stresses reduced according to the Huber-MisesHencky $\sigma(\mathrm{HMH})$ hypothesis, whose values along the column height are shown in fig. 3c.

Secondly, the static analysis (MES) of the elaborated numerical construction of the column was performed. Individual elevation sections of the pole, the LED lantern extension and the photovoltaic panel bracket were loaded with their own weight and the resulting wind velocity pressure, and to the point $M$ the load was reduced from the impact of the wind and the weight of the generator set and the turbine. The directions of applied load and fixing of the column are shown in fig. 3a.

Fig. $3 d$ shows the distribution of stresses in the base of the post and fixing screws. A second numerical simulation was performed for a post with a rectangular opening at a height of $300 \mathrm{~mm}$ and a width of $80 \mathrm{~mm}$ with rounded corners with a radius of $30 \mathrm{~mm}$, for which the distribution of stresses is shown in fig. $3 e$.

\section{Conclusions}

Analysis of the results shows that the largest reduced stresses (Huber-Mises-Hencky) occur at the base of the pole and according to the analytical calculations they reach $99 \mathrm{MPa}$ (fig. 3c). The same location of maximum stresses resulted from the numerical analysis, according to which the value of these stress is $118 \mathrm{MPa}$ (figs. $3 \mathrm{a}$, b). The stress level is already very close to the tensile stresses of $130 \mathrm{MPa}$ for the S275JR steel, while the safety factor for the yield strength $(275 \mathrm{MPa})$ is the smallest value of $n_{b}=2.33$. With the dimensions given in the pole, it is not possible to make a revision hole for the placement of the batteries and the control system, as the stresses along the edge of the opening reach a value of $240 \mathrm{MPa}$ (fig. 3e). In the fixing screws, the base plate of the post reaches $90 \mathrm{MPa}$ (fig. 3d); The screw strength can be reduced as the standard guidelines permit the use of three screws along each edge of the base.

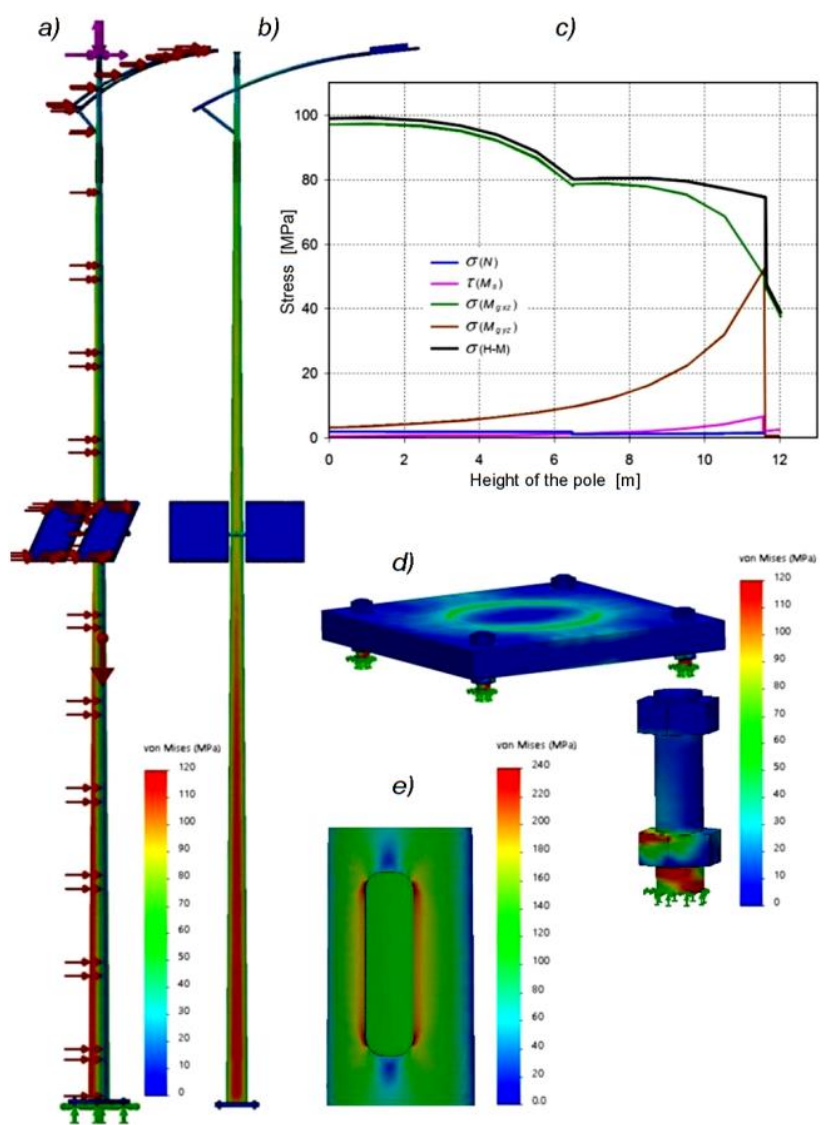

Fig. 3. Stress distribution in the stem and base of the pole

The works were carried out within the framework of the project No. N N 502511940 pt. Functional models and studies on the construction of a quasiautonomous lighting or signaling point.

\section{REFERENCES}

1. Omilianowicz P., Miąskowski W., Nalepa K., Pietkiewicz P. „Analiza koncepcyjna umiejscowienia siłowni wiatrowej na istniejących słupach oświetleniowych". Mechanik. 7 (2015): pp. 613-620.

2. Biuro Inżynierskie SPECBUD. „Porównanie obciążenia wiatrem według Pn-77/B-01011 i według jej zmiany Az1:lipiec2009", http://www.specbud.pl. (2017).

3. EN 40-3-1:2000. Słupy oświetleniowe - Część 1-3: Projektowanie. 